\title{
A IMPORTÂNCIA DO ENSINO DE FILOSOFIA NO ENSINO MÉDIO
}

\author{
Cicera Tenório da Silva ${ }^{1}$ \\ Glauciany Deyvann Tenório de Almeida Sapucaia ${ }^{2}$
}

RESUMO: Nosso objetivo a partir desta pesquisa é pensar a questão do Ensino da Filosofia e do filosofar, partindo de alguns pensamentos filosóficos que marcaram a reflexão sobre a Educação no século XX e neste início do século XXI, bem como apresentar o problema da experiência do homem na atualidade. O decurso desse trabalho e sua elaboração sustentamse no estudo teórico-filosófico. A percepção de uma sociedade entregue à mentalidade pósmoderna tornou-se subsídio para a Filosofia e a Educação, exigindo e propondo a reflexão urgente sobre a banalização da vida, a subserviência ao consumismo desenfreado e a expropriação da experiência. Resgatando a antiga relação entre a Filosofia e a Pedagogia, nos propomos a pensar a experiência na vida e na Educação, especificamente uma experiência que possibilite também a reflexão dos estudantes frente à realidade em que vivem hoje; ou seja, pensamos na urgência de uma Educação que valorize novamente a reflexão filosófica por meio de uma experiência filosófica, tendo-a também como fim. Assim, nossa pesquisa problematiza o Ensino de Filosofia bem como aprofunda o tema da experiência, apresentando sua importância no momento presente. Assim, a Educação e Filosofia são aqui apresentados como uma espécie de tripé formador da vida humana, pois carregam consigo a novidade, o desejo, o inesperado, que são também algumas condições para a experiência humana. Entretanto, essa formação exige a atenção constante, resistindo a imposições, ideologias e programações, resgatando o valor, a necessidade e a compreensão da experiência na atualidade.

Palavras-chave: Ensino de Filosofia. Fracasso escolar. Aprendizagem. Objetivos da Filosofia.

\section{INTRODUÇÃO}

A Filosofia é o estudo das inquietações e problemas da existência humana, existência esta que engloba também muitas das vezes a falta de interesse de alunos em estudar as disciplinas da área de ciências humanas, este problema acontece praticamente em quase todas as escolas, jovens sem perspectivas de vida não investe em seu futuro por diversos motivos, falta de moradia, saúde, pais despreparados e sem formação. Dessa forma muitas das vezes se

\footnotetext{
${ }^{\mathrm{I}}$ Licenciatura em Filosofia pelo Centro Universitário Claretiano. Licenciatura em Pedagogia pela Faculdade de Formação de Professores de Penedo - FFPP. Especialista em Filosofia e Sociologia pela Faculdade FAVENE em parceria com Faculdade Futura. Especialista em Gestão Escolar pela Universidade Federal de Alagoas - UFAL. ${ }^{2}$ Graduação: Bacharelado em Psicologia com Formação de Psicólogo - CESMAC - Centro Universitário Institucional e Clínica. Licenciatura em Letras: Português/Inglês - Faculdade de Tecnologia e Ciências - FTC; Especialista em Psicopedagogia Institucional e Clínica - Faculdade Serigy;.Especialista em Língua Portuguesa e Literatura Brasileira - Faculdade Futura.
} 
torna impossível uma família com este grau de vulnerabilidade investir em conhecimentos. Observa-se, ao longo das décadas, que a precariedade do ensino público brasileiro cada vez mais cresce. Não se consegue, no entanto, delimitar qual seja exatamente o problema, mas alguns podem ser ditos como fundamentadores desta crise como também o despreparo de professores, má remuneração, más condições físicas e didáticas das escolas, falta de professores, falta de material didático, salas com grande número de alunos para apenas um professor, etc. Com todos esses problemas os alunos não recebem a atenção adequada para que o seu processo de construção do conhecimento?

Quando se percebe, portanto, que é necessário dar melhor atenção aos alunos, nem sempre o professor que está na sala de aula possui conhecimento suficiente sobre as dificuldades de aprendizagem e como elas podem ser diagnosticadas e trabalhadas? Não seria, portanto, necessário defini-las e, a partir deste ponto, trabalhá-las para que o aluno não venha a reprovar ou desistir dos estudos?

Portanto, o que se pretende estudar na referida pesquisa é o conhecimento das dificuldades de aprendizagem como um desafio para evitar a repetência e a evasão escolar.

Para que o fracasso e a evasão escolar não tenham seus números cada vez maiores, é necessário que a educação, através da instituição escolar, esteja cada vez mais conectada às novas tecnologias e, principalmente, ao público que pretende alcançar. No caso dos jovens, entender e utilizar as novas tecnologias, bem como o turbilhão de informações que chegam dia-a-dia é de suma importância para que o mesmo tenha sucesso na escola e que se sinta estimulado para continuar nela e, desse modo, ter uma expectativa de emprego maior e melhor após sua formatura.

Dentre os diversos problemas que o sistema público de educação brasileiro atravessa há algumas décadas, observa-se que a repetência e a evasão escolar estão em crescente escala e os motivos podem ser diversos. Dentre eles, acredita-se que exista, quando se trata da repetência, de dificuldades apresentadas pelos alunos e não sanadas pelo professor e em se tratando da evasão, a desmotivação do aluno perante um sistema de ensino que não está acrescentando na construção de seu conhecimento. 
Neste sentido, é possível observar que a não observância das dificuldades de aprendizagem dos alunos podem fazer com que os mesmos reprovem de série e, até mesmo, se desmotivem em continuar seus estudos. Dessa forma, percebe-se que as dificuldades de aprendizagem são um grande desafio no combate à repetência e à evasão escolar.

Diagnosticar as dificuldades de aprendizagem do aluno é um grande passo para um processo de ensino e aprendizagem de qualidade para o mesmo, mas a capacidade de trabalhálas por parte do professor é um instrumento precioso em todo o processo. Por esta razão, entender o que são e quais são as dificuldades de aprendizagem bem como saber superá-las tanto por parte dos alunos como dos professores com certeza diminuirá os índices de reprovação e de evasão escolar.

De forma geral a Filosofia busca um relacionamento com o ensino, uma vez que as escolas, tem a obrigação de preparar indivíduos para o exercício no mundo da criticidade, principalmente no que diz respeito a investimento dos jovens. Portanto, necessário se faz defini-lá a partir do ponto de partida da criticidade de cada contexto social. Assim, a Filosofia, é de grande importância na formação, pessoal, intelectual e psicológica de cada ser.

Diante das diversas definições a respeito do ensino de Filosofia, um fator que permanece em evidência é a importância das pessoas no ambiente escolar e na vida publica. $O$ homem, ao produzir os meios para a satisfação de suas necessidades básicas existentes, ao produzir uma realidade humanizada pela sua atividade, humaniza a si próprio. Este homem, constitui portanto uma grande importância na evolução intelectual, ele precisa aprender a aprender conviver com as diversas diferenças, e aprender a aceitar a opinião de outro indivíduo, este ser que aprendeu a pensar intelectualmente pode até questionar de forma a colocar o seu ponto de vista, mas jamais apontar uma falha no pensamento do outro.

Dai resulta o reencontro da filosofia com a educação, as reflexões oriundas da filosofia abrem-se à eterna novidade do pensamento e da disposição para a construção de um ideal de felicidades para todos, amplos espaços parra entender o papel do sujeito pensante, a necessidade da lucidez científica e a paixão pela intelectualidade, sem a determinação da prática do saber inacabado. A palavra Filosofia da educação, tem em comum o fato de serem 
ações humanas? Tem em comum na medida em que o trabalho humano seja um esforço para o crescimento de uma sociedade.

Os objetivos do Ensino de Filosofia no ensino médio ou em qualquer etapa da educação, visam alcançar exatamente a evolução intelectual e de criticidade de cada indivíduo. Isso, porque a medida que o indivíduo passe a se identificar com as finalidades da filosofia, existe a possibilidade de se tornar um conceituado profissional relacionado ao sucesso. Um dos passos a ser realizado para alcançar o objetivo de pessoa ou profissional de sucesso e dar sua contribuição no mercado de trabalho, enfatizando a área da educação é verificar suas estratégias que possam contribuir em seu crescimento.

\section{DESENVOLVIMENTO}

Diante de um novo rumo que está preste a levar ou que levou o ensino de Filosofia e Sociologia como disciplinas independentes e obrigatórias. Agora aparecem diluídas na área Ciências Humanas e Sociais Aplicadas, a exemplo do que ocorrerá com as disciplinas de Geografia, História e Sociologia.

Mas afinal qual o papel do Ensino de Filosofia? A Filosofia é de fundamental importância na vida do ser humano em geral, visto que proporciona a prática de análise, reflexão, pensamento argumentativo e crítico-reflexivo, em benefício do encontro do conhecimento do mundo e do homem. O Ensino Fundamental e Médio é geralmente considerado por educadores e especialistas em educação, como uma fase de consolidação de crianças e adolescentes, de sua personalidade e seus anseios, portanto a Filosofia apresenta um papel importante e fundamental no sentido de integração e colaboração nessa formação. Essa "formação" dá ao aluno a capacidade de torna-se cidadão ativo consciente dos seus direitos e deveres, bem como de buscar por meio da reflexão melhoria na condição atual do mundo vigente. A essência da filosofia frente às outras disciplinas está no fato da mesma trabalhar com conceitos, e não com definições prontas e acabadas, mas com a possibilidade de questionamentos que exigindo reflexão, uma vez que o pensamento não é algo estático, mas dinâmico.

Acontece que houve mudança na BNCC, a qual criou muita polêmica, principalmente entre os educadores e especialistas em educação, que entendem ser fundamental o ensino da 
Filosofia e Sociologia na educação de base, e que vem enfrentando forte oposição no Congresso Nacional. Existem várias propostas nesse sentido como a Sugestão Legislativa no 20 de 2018 que tramita no Senado.

Acho que seria mais fácil então, perguntar: A quem não interessa? É fácil concluir que a formação de jovens eleitores com pensamento argumentativo e crítico-reflexivo, cidadãos ativos e participantes na vida política do País, mudaria radicalmente o perfil da maioria dos atuais eleitores. E a quem isso não interessa.

Para o desenvolvimento do presente trabalho foi utilizado pesquisa bibliográficas. A pesquisa bibliográfica baseou-se em publicações científicas da área de educação, em sua totalidade.

Entender para quem o ensino está voltado é de suma importância para que todo o processo de ensino aprendizagem tenha sucesso quando este ocorra. Não basta, mais entender que o ensino é voltado à crianças, adolescentes e jovens que visam adquirir conhecimentos pré-estabelecidos como necessários para cursar uma universidade, para obter um diploma e, desse modo, ter uma remuneração melhor daqueles conhecidos como técnicos.

Deve-se, portanto, observar para que tipo de indivíduo o ensino esteja sendo desenvolvido e qual a comunidade a escola responde seus serviços. Dessa forma, tendo sempre em vista o que se pretende e a quem se pretende é possível fazer com que a formação acadêmica tenha um sentido que não seja apenas a atuação no mercado de trabalho, mas para a formação total de um ser humano que possa ser capaz de entender e atuar sua realidade.

Desse modo, a educação pública como aparece, hoje, na mídia brasileira e que é possível ser observada sob diversos olhares de estudos científicos acerca do tema educação, está totalmente desmotivadora para esses jovens que cada dia exige mais da sociedade da mesma forma que esta demanda do jovem. Neste sentido, uma educação defasada e com instituições sucateadas bem como políticas ultrapassadas e ineficazes faz com que a qualidade seja enormemente inferior se comparadas ao sistema particular de ensino, fora que a educação pública brasileira cresce em quantidade, mas a qualidade cai em larga escala. 
Portanto a autora confirma a existência dessa exclusão e como ela é, muitas vezes contestada pelos jovens:

La anarquía, los graffitis urbanos, los ritmos tribales, los consumes culturales, la búsqueda de alternativas y los compromisos itinerantes, deben ser leídos como formas de actuación política no institucionalizada y no como las practicas, mas o menos inofensivas de un montón de desadaptados (CRUZ, 2000, p. 3).

Como pode-se observar a sociedade, seja ela que tipo for, impõe certas características às suas instituições e aos seus indivíduos e estes tomam suas formas conforme as demandas que a sociedade coloca. E a escola é uma das instituições que não fogem à esta regra. Ela deve, através da educação, atender às demandas de uma sociedade voltada à acumulação de capital e à lógica do mercado. Desse modo, a escola visa formar força de trabalho para atuar no mercado atendendo a necessidade capitalista.

Assim, a Educação não estaria presa à escola somente, nem a um espaço e um tempo determinados. Teria que haver a disponibilidade de todos ao aprender, uma disposição que levaria uma vida toda, aprendendo sempre, em cada momento e idade.

Não se é necessariamente feliz com o saber. Saber supõe que uns admitam que não sabem e que os outros, aqueles que é suposto saberem e ensinarem, não cessem de medir a extensão do que lhes resta ainda para aprender, com o esforço, o trabalho, a disciplina que isso implica. (LYOTARD, 1993a, p. 52).

$\mathrm{Na}$ verdade, vivemos de acordo com um saber legitimado e imposto, o qual é expresso e ensinado primeiramente na escola. Hoje a legitimação do saber está disposta a uma questão e condição política; a democratização da ciência, de modo que "todos tenham acesso" a ela e conheçam as bases do desenvolvimento científico e tecnológico. Assim, o povo, afirma o discurso legitimador, quer saber, quer ter a instrução e cobra isso do Estado. O Estado, por sua vez, atende ao apelo e "oferece" ao povo a formação escolar, institucionalizada, conservando a idéia de que está formando uma nação e orientando o caminho do progresso, ambos sendo atendidos em seus anseios.

Fundada nesse sistema, a nação está longe de deliberar sobre o saber e o conhecimento ou informação. É saber aquilo que é dado e institucionalizado através do Estado, e é verdade o que é ditado por um jogo de linguagem9, um discurso que orienta a prática ética, social e política. A vontade subjetiva e a disposição para conhecer, inerentes ao ser humano, deixam 
de existir, devendo cumprir o que já está determinado pelos programas e pela burocracia organizada da instituição.

\begin{abstract}
Esse saber legitimado tem sido orientado em suas raízes não por um Estado que dá espaço ao seu povo, base constitucional da nação, mas por um espírito especulativo, filosófico, o qual só é proferido por alguns que tenham a autoridade para falar e expressar a verdade instituída pelo jogo de linguagem, representando a autoridade do Estado. "O sujeito do saber não é o povo, é o espírito especulativo. Ele não se encarna, como na França de após Revolução, num Estado, mas num Sistema. O jogo de linguagem de legitimação não é político-estatal, mas filosófico." (LYOTARD, I999, p. 6r).
\end{abstract}

É importante afirmar que o papel de educadores e estudiosos em Educação, de uma forma ou de outra, dizem que é de vital importância atualizar os métodos de ensino, principalmente o do ensino público, investir no desenvolvimento da carreira do docente, isto é, no seu aprimoramento e motivação, e, tudo isso, alinhado com o perfil do aluno do século XXI e sua forma de vida lastreada pela tecnologia e rapidez da comunicação. Então, como ensinar Filosofia com o tempo necessário que a sua apreensão necessita e com toda a sua abstração? Independente dos caminhos pedagógicos e filosóficos, não podemos deixar de citar e ressaltar a importância dos papéis que cada um exerce nesse processo educacional, ou

seja, o da Escola, dos Pais, dos Docentes e dos Alunos, e ainda, e principalmente, o do Estado, como Politéia responsável pela Paidéia. Não é foco aqui entrar nas dificuldades e recursos de cada uma dessas áreas da vida, digamos assim, mas é importante não esquecê-las e, principalmente, ter a lucidez de que sem um esforço desse todo, cada parte sai, para mais ou menos, com um certo agravo.

\title{
3. CONSIDERAÇÕES FINAIS
}

Analisando e buscando entender, principalmente o pensamento filosófico, podemos imaginar que se despontava na época e que se opunha à Doutrina Oficial da Coroa atrelada à Igreja, permaneceu desconhecido ou destruído pelas autoridades por contrariar as idéias permitidas para difusão ou por escreverem e pensarem coisas novas e diferentes das permitidas naquela realidade. A maior parte das obras que receberam atenção e edição era de caráter descritivo, expondo os supostos valores do Brasil para a Coroa Portuguesa. Nesse sentido, predominava a impossibilidade da discussão filosófica e da emergência do pensamento brasileiro a partir de uma realidade própria. Durante os séculos XVII e XVIII, então, não foi possível ainda uma consolidação do pensamento brasileiro, pois as principais e 
permitidas idéias a serem difundidas vinham de fora, da Europa, havendo uma espécie de mistura de idéias portuguesas com uma realidade brasileira, podendo ser considerada época de um pensamento luso-brasileiro.

Segundo Lyotard, houve uma espécie de passagem da era moderna para a pósmoderna: porém, não sendo cronológica, é uma passagem que demarca a diferença de uma formação orientada pelas grandes narrativas de outra que inicia um processo de orientação a partir de um conjunto de narrativas (Cf. LYOTARD, 1993 b, p. 49) com variados estilos de vida e jogos de linguagem que não mais privilegiam a sua legitimação. E esses nomes não dizem respeito tanto à era, à época em que nossos parentes viveram no final do século XVIII e no XIX ou em qualquer outro momento, senão ao ambiente criado por um pensamento que dirigiu o pensamento dos demais. "Nesses termos, para o filósofo francês, a pós-modernidade não seria o que vem depois da modernidade, cronológica e historicamente falando, mas o que vem antes e a acompanha [...]" (PAGNI, 2006a, p.578). Por exemplo, o século das luzes tinha o intuito de libertar a humanidade do despotismo político, bem como da ignorância da grande maioria e de sua miséria; por isso, este pensamento está ligado a uma meta narrativa criada e fortemente difundida naquela época.

Ao mesmo tempo, são épocas marcadas por ideais; os de libertação dos indivíduos e do progresso de toda a humanidade. Foram finalmente vencidos e banalizados, mas não deixaram de ser ideais fortes e que reuniam multidões. Hoje, na era das ciências, não falamos mais em progresso da humanidade pelos ideais, mas em "desenvolvimento" das ciências e das técnicas, as quais norteiam a vida do homem em todo o seu comportamento. Perguntamos hoje quais são os nossos ideais, como professores formadores de opinião e de pensamento, e não temos resposta, pois o que distingue nossa época é "a incerteza em que nos encontramos quanto à possibilidade de pensar os nossos objetivos. $\mathrm{O}$ mal estar dos docentes provém, e parte, daí: eles já não sabem qual é a finalidade da sua atividade.” (LYOTARD, 1993a, p. 50).

Se, por um lado, hoje, a Educação se prende em transmitir conhecimentos sobre tudo o que se pode conhecer, desde as células humanas até a constituição do universo (e as galáxias por especulação), Lyotard nos chama a atenção para uma razoável finalidade da Educação: "Seria a de tornar as pessoas mais sensíveis às diferenças, de fazê-las sair do pensamento massificante. É preciso educar, instruir, nutrir o espírito de discernimento, formar para a complexidade." (LYOTARD, i993a, p. 5o). 
O problema está em não pretender que as pessoas pensem sobre a história, os acontecimentos, a sociedade e suas relações políticas. A tendência de nosso sistema político e de nossa Educação formalmente estruturada é a de "educar em massa". E essa massificação é o pior ambiente que se possa criar dentro de um sistema que pretende o progresso. É preciso que as pessoas pensem a complexidade das coisas e suas relações, resistindo e refreando tudo o que tende ao simplismo e massificante: a escolaridade obrigatória ou "para todos" é um exemplo de Educação simples e em massa. Ainda que ela tenha um sentido fecundo, poucos são os que alcançam um pensamento melhor elaborado e espírito filosófico, perguntando sobre si, sobre sua realidade e sobre possíveis mudanças no sistema educacional e social.

\section{REFERÊNCIAS BIBLIOGRÁFICAS}

CARRANO, P. e PEREGRINO, M. O direito à juventude na escola que se expande: desafio para a democratização da escola pública no Brasil. Artigo originalmente publicado com o título La escuela em expansión: un desafio para los jóvenes. In: Revista Anales de la educación común. Buenos Aires: Dirección General de Cultura y Educación - Gobierno de la Provincia de Buenos Aires. Tercer siglo. Anõ I - números I-2, septiembre, 2005. ISSN I6694627 , pp i8-27.

CANCLINI, N. Donde esta la caja de herramientas? Cambios culturales, jovenes y educacion. Seminario internacional "La formación docente en los actuales escenarios: desafíos debates, perspectivas". I9 de abril de 2006 en la Universidad de La Matanza, Florencio Varela 1903, San Justo, Provincia de Buenos Aires.

CRUZ, R.R. Emergência de culturas juveniles: estrategias del desencanto. Enciclopédia Latino Americana de Sociocultura y Comunicación. Buenos Aires: Editorial Norma, 2000.

FANFANI, E. Culturas juveniles y cultura escolar. Documento presentado al seminario "Escola Jovem: un novo olhar sobre o ensino médio. Organizado por el Ministerio da Educaçao. Secretaria de Educaçao Média e Tecnológica. Coordenaçao-Geral de Ensino Médio. Brasilia, del 7 al 9 de junio del 200o. Buenos Aires, 2000.

JACINTO, C. et al. Formacion para el trabaljo de jovenes de sectores de probreza em America Latina: que desafios y que estrategias.

LASIDA, J. Estrategias para acercar as los jovenes ao trabajo. Buenos Aires: Red Etis, 2004.

LEITE, E. Cultura juvenil: faça você mesmo. Disponível em: http://www.acaoeducativa.org.br/portal/images/stories/pdfs/artigolemonde.pdf2oo9. Acesso em 29/o6/2009. 
PACCA, S. Desinteresse leva à evasão escolar. O Diário de Mogi Online - SP. 17/o4/2009. Acesso em 19/06/2009.

SPOZATI, A. Exclusão social e fracasso escolar. Rev. Em Aberto, Brasília, v.17, n.71, p.21-32, janeiro de 2000.

TIRAMONTI, G. Procesos de invidualización em jovenes escolarizados. Rev. MIE, abril/jun 2006, v.II, n.29.

ARANTES, Paulo Eduardo. Um departamento francês de Ultramar: estudos sobre a formação da cultura filosófica uspiana. Rio de Janeiro: Paz e Terra, 1994. 